\title{
Burnout Syndrome during Pediatric Residency Training
}

\author{
Fadi M. Jan, Mohammed M. Jan \\ Department of Pediatrics, Faculty of Medicine, King Abdulaziz University, Jeddah, Kingdom of Saudi Arabia \\ Email: mmjan@kau.edu.sa
}

Received 8 July 2015; accepted 28 August 2015; published 31 August 2015

Copyright (C) 2015 by authors and Scientific Research Publishing Inc.

This work is licensed under the Creative Commons Attribution International License (CC BY). http://creativecommons.org/licenses/by/4.0/

(c) (i) Open Access

\section{Abstract}

Background: Burnout syndrome is a common professional problem causing mental fatigue, depersonalization, and diminished self-value. Burnout during pediatric residency can significantly influence the resident's performance and the quality of their training. Objectives: To evaluate the burnout status of pediatric residents across Jeddah, KSA. Methods: A cross-sectional, descriptive study involving pediatric residents across Jeddah, Saudi Arabia was conducted from the $1^{\text {st }}$ of August to $1^{\text {st }}$ of December, 2012. The Maslach Burnout Inventory was utilized in addition to questions about their work environment and lifestyle. Results: Sixty pediatric residents $(67 \%$ females $)$ were included with ages ranging between 25 - 30 years (mean 26.5). They practiced in various institutions, mostly $(41 \%)$ in ministry of health hospitals. Burnout scores were abnormal in $49(82 \%)$ and in $19(32 \%)$ the syndrome was severe. Males were more likely to reach a severe burnout category when compared to females $(32 \%$ vs $19 \%, p=0.01)$. Residents working in the university hospital $(23 \%)$, were more likely to have severe burnout when compared to those working in other hospitals $(p=0.002)$. Junior residents (R1 and $R 2)$ were also more likely to have severe burnout when compared to senior residents $(34 \%$ vs $21 \%, p=0.013)$. Conclusions: Many pediatric residents are suffering from burnout syndrome. It is more common among males, junior residents, and those working in a university hospital setting. Specific strategies should be developed to prevent resident burnout.

\section{Keywords}

Burnout Syndrome, Pediatrics, Residents, Training, Practice

\section{Introduction}

Burnout syndrome is a common problem affecting health care workers and causing mental fatigue, depersonali- 
zation, and diminished self-value [1]-[4]. Affected individuals are unable to cope with the ongoing work stress resulting in negative feelings and attitudes toward their medical team members and patients. If burnout syndrome continues with no intervention, it will progress and eventually result in dissatisfaction with work and training [5]. In general, burnout syndrome is more prevalent in stressful environments that are physically demanding or requiring higher levels of commitments, such as pediatric residency programs [6]. During such training, the resident is expected to have frequent in-house calls, participate in invasive procedures, and look after patients requiring intensive or emergent care [7]. Some pediatric rotations could be more stressful and demanding than others, including emergency or intensive care services, neonatology, oncology, and neurology [8][10]. Looking after patients with progressive or untreatable conditions may further increase their level of frustration and emotional stress. Pediatric residents are also often confronted by anxious or fatigued parents. This further adds to their work stress. Lack of sleep and fatigue because of frequent and busy in-house calls was perceived by many residents to have a major impact on their personal lives and their ability to perform their work [11]. All these factors contribute to burnout, which in turn affects the resident's performance and the quality of their training. This area received limited previous study. Therefore, this study was designed to evaluate burnout status of pediatric residents across training programs in Jeddah, KSA and explore possible contributing and correlating factors. We hypothesize that many pediatric residents are suffering from burnout syndrome.

\section{Methods}

A cross-sectional, descriptive study involving pediatric residents across the Jeddah area of Saudi Arabia was conducted over 4 consecutive months ( $1^{\text {st }}$ of August to $1^{\text {st }}$ of December, 2012). Pediatric residents at various levels of training were included. They were enrolled from various pediatric residency training programs in Jeddah, Saudi Arabia, including university, ministry of health, military, and other major hospitals. The Maslach Burnout Inventory was utilized to examine three domains including emotional exhaustion, depersonalization, and personal accomplishment at work as summarized in Table 1 [5]. The original English version was used. Demographic variables and questions regarding work and lifestyle-related factors that could correlate with burnout were also included (Table 2). The study design and questionnaires were approved by King Abdulaziz University

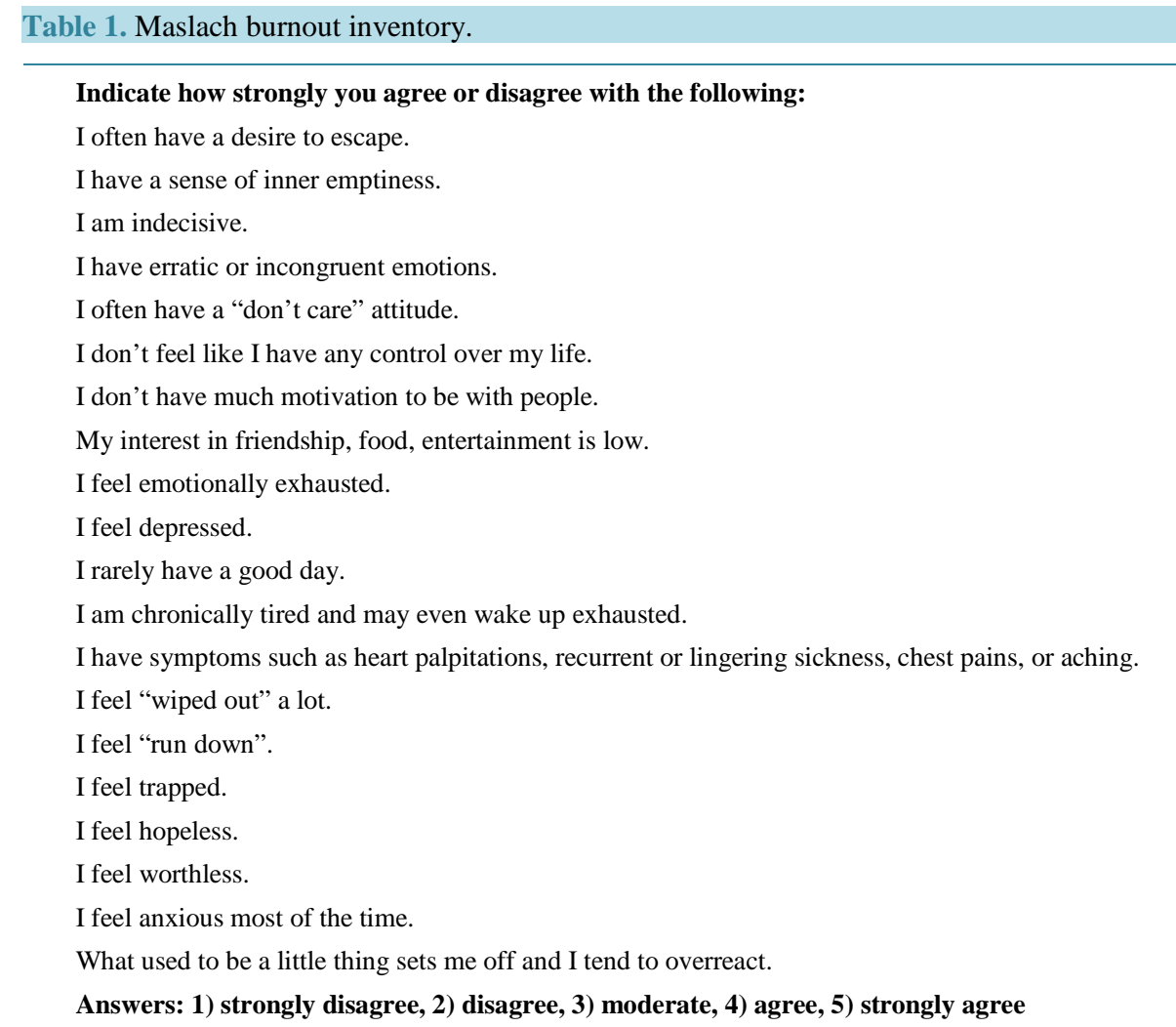


hospital ethics committee. The questionnaires were distributed to program directors to maximize the response rate. Before consenting for the study, all included residents were assured that their participation is voluntary and that the collected data will be confidential.

Data were collected in Excel sheets and statistical analysis was performed using SPSS 17 (SPSS, Inc., Chicago, IL, USA). Descriptive analyses were performed and the variables were examined in $2 \times 2$ tables using chi-square test. Statistical significance was defined as $\mathrm{P}$ values of less than 0.05 .

\section{Results}

Seventy two questionnaires were distributed and 60 (83\%) were returned. Of these 60 pediatric residents, $67 \%$ were females with ages ranging between 25 - 30 years (mean 26.5, SD 2.3). Most residents (61\%) were single and 29\% had children of their own ranging in number from 1 - 3 (mean 1.5). Most of those included (67\%) were junior residents in their first 2 years of training. The majority practiced in a ministry of health hospital (41\%) or the university hospital (23\%) with variable monthly income depending on the sponsor of their position.

Burnout scores were abnormal in 49 (82\%) and in 19 (32\%) the syndrome was severe (Table 3). The resident's sex, hospital setting, and training level correlated with their burnout status. Males were more likely to reach a severe burnout category when compared to females (32\% vs $19 \%, \mathrm{p}=0.01)$. Residents working in the university hospital (23\%), were more likely to have severe burnout when compared to those working in other hospitals $(p=0.002)$. Finally, junior residents (R1 and R2) were also more likely to have severe burnout when compared to senior residents ( $34 \%$ vs $21 \%, \mathrm{p}=0.013$ ). Age, marital status, and income had no correlation with burnout status. Those with other significant stresses in their lives (Table 2) constituted 14\%. This factor was not reflected on their burnout scores. This was also true for those with history of other medical (16\%) or psychiatric (2\%) illness.

Table 2. Factors that were evaluated for possible correlation with severe burnout.

Personal factors

1) Age

2) Sex $^{*}$

3) Marital status

4) Number of children if any

5) History of medical or psychiatric illness

Work-related factors

1) Work type (junior, senior)

2) Hospital type (ministry of health, university, military, other) ${ }^{*}$

3) Number of in house calls

4) Number of clinics per week

5) Monthly income

Other possible sources of stress over the last year

1) Loss of a child

2) Loss of a partner

3) Loss of a parent

4) Financial loss

5) Job change

*Factors associated with severe burnout $(\mathrm{p}<0.05)$.

Table 3. Burnout severity scores in the study sample $(n=60)$.

\begin{tabular}{|c|c|c|}
\hline \multicolumn{2}{|r|}{ Burnout scores } & Number (percentage) \\
\hline 1) & Normal (20 - 30) & $11(18 \%)$ \\
\hline 2) & Abnormal (>30) & 49 (82\%) \\
\hline & a) Mild (31 - 40) & $14(23 \%)$ \\
\hline & b) Moderate (41 - 60) & $16(27 \%)$ \\
\hline & c) Severe $(61-80)$ & 19 (32\%) \\
\hline
\end{tabular}




\section{Discussion}

This study confirms that many pediatric residents are suffering from burnout syndrome. Few other studies assessed the prevalence of burnout syndrome in pediatric healthcare workers, which reached $41 \%$ of hospital workers attending pediatric patients [12]-[14]. In other studies, burnout and depression were found to be major problems among pediatric residents resulting in significant medical errors [15] [16]. In our study, males, junior residents, and those working in the university hospital were at increased risk of burnout syndrome. Other authors found females at higher risk of developing burnout in an oncology study [17]. This may not apply to other rotations that deal with less life threatening illnesses. In general, females prefer a career in pediatrics when compared to males [18]. This may explain a higher work satisfaction and therefore less burnout risk. We also found that junior residents (R1 and R2) were more likely to have burnout when compared to more senior residents. Increased work load, responsibilities, and reduced experience may explain this trend. Sleep loss and fatigue is also more common during these years because of more frequent in-house calls, adding to increased risk of burnout. An additional possible contributing factor is frequent "paging". "Beepers" were found to frequently interrupt pediatric residents involved in patient care activities and scheduled educational conferences [19]. Finally, higher burnout levels in residents training in the university hospital can be explained by the increased burden of work that includes teaching and supervising medical students and interns, and participating in periodic medical school exams. This increased risk of burnout was previously reported in a study of medical residents in a teaching hospital [20]. Age, marital status, and income had no correlation with burnout status. Those with other significant stresses in their lives were not at an increased risk of burnout. The lack of significant associations may be related to our relatively small numbers.

Burnout is a common problem that has to be addressed and highlighted in pediatric residency programs. Specific strategies should be developed and implemented to prevent or limit burnout keeping in mind its negative effects on patient safety. This is particularly relevant in our region where this problem is not well studied [21] [22]. Resident well-being is closely connected to professional development and required some varying degrees of self-sacrifice and rebalancing of personal priorities, all dependent on the resident her/himself [23]. The findings of this study should be considered by training programs that are interested in enhancing resident well-being. Affected pediatric residents may develop negative attitudes toward self and professional activity, and eventually lose interest in pediatric care, have low productivity, and self-esteem. Routine exercise should be encouraged and promoted as it is associated with lower burnout scores [17] [24]. Physicians who are satisfied with their lives outside of work are also less likely to have burnout. Periodic social and community activities should be encouraged and promoted during residency. The availability of direct communication with program directors with periodic meetings for debriefing could also prevent burnout. Finally, more research is needed in this area, particularly regarding the development and implementation of effective interventions aimed at preventing and treating resident's burnout.

\section{Conclusion}

To conclude, at least one third of pediatric residents training in the Jeddah region are suffering from burnout syndrome. This finding further substantiates the growing concern about the potential impact of burnout on professional development. These observations should be taken into account in developing new training guidelines and educational interventions for pediatric residents.

\section{Acknowledgements}

The author acknowledge with thanks Dr. Bakr M. Bin Sadiq for his statistical advice and guidance. I am also grateful to Dr. Ahmed Khan and Dr. Reem Al-Youbi for helping in distributing some of the questionnaires.

\section{References}

[1] Al-Youbi, R.A. and Jan, M.M. (2013) Burnout Syndrome in Pediatric Practice. Oman Medical Journal, 28, $252-254$. http://dx.doi.org/10.5001/omj.2013.71

[2] Maslach, C., Schaufeli, W.B. and Leiter, M. (2001) Job Burnout. Annual Review of Psychology, 52, 397-422. http://dx.doi.org/10.1146/annurev.psych.52.1.397

[3] Teng, C.I., Chang, S.S. and Hsu, K.H. (2009) Emotional Stability of Nurses: Impact on Patient Safety. Journal of Ad- 
vanced Nursing, 7, 221-224. http://dx.doi.org/10.1111/j.1365-2648.2009.05072.x

[4] Della Valle, E., De Pascale, G., Cuccaro, A., Di Mare, M., Padovano, L. and Carbone, U. (2006) Burnout: Rising Interest Phenomenon in Stressful Workplace. Ann Ig, 18, 171-177.

[5] Maslach, C. and Jackson, S.E. (1981) The Measurement of Experienced Burnout. Journal of Organizational Behavior, 2, 99-113. http://dx.doi.org/10.1002/job.4030020205

[6] Lesic, A.R., Stefanovic, N.P., Perunicic, I., Milenkovic, P., Tosevski, D.L. and Bumbasirevic, M.Z. (2009) Burnout in Belgrade Orthopaedic Surgeons and General Practitioners, a Preliminary Report. Acta Chir Iugosl, 56, 53-59.4.

[7] Balch, C.M. and Shanafelt, T. (2010) Combating Stress and Burnout in Surgical Practice: A Review. Advances in Surgery, 44, 29-47. http://dx.doi.org/10.1016/j.yasu.2010.05.018

[8] Horiguchi, T., Kaga, M., Inagaki, M., Uno, A., Lasky, R. and Hecox, K. (2003) An Assessment of the Mental Health of Physicians Specializing in the Field of Child Neurology. Journal of Pediatric Nursing, 18, 70-74. http://dx.doi.org/10.1053/jpdn.2003.16

[9] Jan, M.M. (2004) Perception of Pediatric Neurology among Non-Neurologists. Journal of Child Neurology, 19, 1-5.

[10] Reader, T.W., Cuthbertson, B.H. and Decuyenaere, J. (2008) Burnout in the ICU: Potential Consequences for Staff and Patient Well-Being. Intensive Care Medicine, 34, 4-6. http://dx.doi.org/10.1007/s00134-007-0908-4

[11] Papp, K.K., Stoller, E.P., Sage, P., Aikens, J.E., Owens, J., Avidan, A., Phillips, B., Rosen, R. and Strohl, K.P. (2004) The Effects of Sleep Loss and Fatigue on Resident-Physicians: A Multi-Institutional, Mixed-Method Study. Academic Medicine, 79, 394-406.http://dx.doi.org/10.1097/00001888-200405000-00007

[12] Bustinza Arriortua, A., Lopez-Herce Cid, J., Carrillo Alvarez, A., Vigil Escribano, M.D., de Lucas Garcia, N. and Panadero Carlavilla, E. (2000) Burnout among Spanish Pediatricians Specialized in Intensive Care. Asociación Española de Pediatría, 52, 418-423. http://dx.doi.org/10.1016/S1695-4033(00)77373-5

[13] Lopez Franco, M., Rodriguez Nunez, A., Fernandez Sanmartin, M., Marcos Alonso, S., Martinon Torres, F. and Martinon Sanchez, J.M. (2005) Burnout Syndrome among Health Workers in Pediatrics. Anales de Pediatría, 62, $248-251$.

[14] Pistelli, Y., Perochena, J., Moscoloni, N. and Tarres, M.C. (2011) Burnout Syndrome among Pediatricians. Bivariate and Multivariate Analysis. Archivos Argentinos de Pediatria, 109, 129-134.

[15] Landrigan, C.P., Fahrenkopf, A.M., Lewin, D., Sharek, P.J., Barger, L.K., Eisner, M., Edwards, S., Chiang, V.W., Wiedermann, B.L. and Sectish, T.C. (2008) Effects of the Accreditation Council for Graduate Medical Education Duty Hour Limits on Sleep, Work Hours, and Safety. Pediatrics, 122, 250-258. http://dx.doi.org/10.1542/peds.2007-2306

[16] Fahrenkopf, A.M., Sectish, T.C., Barger, L.K., Sharek, P.J., Lewin, D., Chiang, V.W., Edwards, S., Wiedermann, B.L. and Landrigan, C.P. (2008) Rates of Medication Errors among Depressed and Burnt out Residents: Prospective Cohort Study. British Medical Journal, 336, 488-491. http://dx.doi.org/10.1136/bmj.39469.763218.BE

[17] Roth, M., Morrone, K., Moody, K., Kim, M., Wang, D., Moadel, A. and Levy, A. (2011) Career Burnout among Pediatric Oncologists. Pediatric Blood \& Cancer, 57, 1168-1173.

[18] Al-Asnag, M.A. and Jan, M.M. (2002) Influence of the Clinical Rotation on Intern Attitudes toward Pediatrics. Clinical Pediatrics, 41, 509-514. http://dx.doi.org/10.1177/000992280204100708

[19] Blum, N.J. and Lieu, T.A. (1992) Interrupted Care. The Effects of Paging on Pediatric Resident Activities. American Journal of Diseases of Children, 146, 806-808. http://dx.doi.org/10.1001/archpedi.1992.02160190038016

[20] Ringrose, R., Houterman, S., Koops, W. and Oei, G. (2009) Burnout in Medical Residents: A Questionnaire and Interview Study. Psychology, Health \& Medicine, 14, 476-486. http://dx.doi.org/10.1080/13548500903012822

[21] Al-Turki, H.A. (2010) Saudi Arabian Nurses. Are They Prone to Burnout Syndrome? Saudi Medical Journal, 31, 313316.

[22] Sadat-Ali, M., Al-Habdan, I.M., Al-Dakheel, D.A. and Shriyan, D. (2005) Are Orthopedic Surgeons Prone to Burnout? Saudi Medical Journal, 26, 1180-1182.

[23] Ratanawongsa, N., Wright, S.M. and Carrese, J.A. (2007) Well-Being in Residency: A Time for Temporary Imbalance? Medical Education, 41, 273-280. http://dx.doi.org/10.1111/j.1365-2929.2007.02687.x

[24] Fields, A.I., Cuerdon, T.T., Brasseux, C.O., Getson, P.R., Thompson, A.E., Orlowski, J.P. and Youngner, S.J. (1995) Physician Burnout in Pediatric Critical Care Medicine. Critical Care Medicine, 23, 1425-1429. http://dx.doi.org/10.1097/00003246-199508000-00018 